\title{
Interview
}

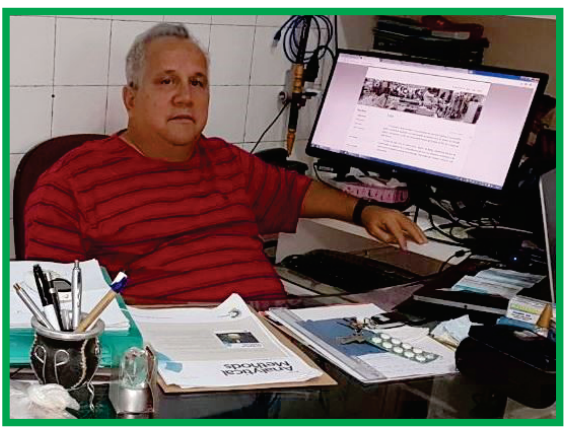

\section{Professor Mário Ugulino, who is an active member of the scientific community, recently spoke with BrJAC}

Mário César Ugulino de Araújo

Full Professor at the Department of Chemistry, Center of Exact and Nature Sciences, Federal University of Paraíba, PB, BR laqa@quimica.ufpb.br

Since 1988, Prof. Mário Ugulino, as he is best known, has been the coordinator of the Laboratory of Automation and Instrumentation in Analytical Chemistry and Chemometrics (LAQA) of the Department of Chemistry, Center of Exact and Nature Sciences (CCEN), at the Federal University of Paraíba, Campus I, João Pessoa, Paraíba, Brazil. The LAQA is a consolidated laboratory in the northeast region of Brazil, specializing in the areas of analytical instrumentation, automation of analytical processes, and chemometrics.

Prof. Mário is currently a research productivity fellow of the National Council for Scientific and Technological Development (CNPq) at level 1A. He holds a degree in industrial chemistry from the Federal University of Paraíba (UFPB) and a PhD in chemistry from the University of Campinas (Unicamp), São Paulo, Brazil.

The title of his PhD thesis was "Development of automated systems of standard additions and elimination of interferences in spectrophotometric analyses of rocks, minerals, and alloys by applying the generalized standard addition method". His advisor was Prof. Dr. Roy Edward Bruns, one of the pioneers in the development of computational quantum chemistry and chemometrics in Brazil. Mário Ugulino, Elias Ayres Guidetti Zagatto, and leda Spacino Scarminio were the first students taught in Brazil by Prof. Bruns in Chemometrics. Mário Ugulino's doctorate involved the development of automated flow injection analysis (FIA) systems and relied on the collaboration with good friends Boaventura Freire dos Reis, Francisco José Krug, Elias Zagatto, and Henrique Bergamin Filho, from the Center for Nuclear Energy in Agriculture (CENA) at the University of São Paulo, and Celio Pasquini from Unicamp. The chemometrics he used in data processing, especially the generalized standard addition method (GSAM), he developed with the invaluable help of his advisor and friends at Unicamp and CENA. He was also reliant on the expressive scientific cooperation in chemometrics from Prof. Dr. Roberto Kawakami Harrop Galvão, based in the Electronic Engineering Division of the Technological Institute of Aeronautics (ITA), São José dos Campos, São Paulo, Brazil.

Since February 1982, Mário Ugulino has been Professor of the Department of Chemistry at the CCEN of the UFPB. He could have retired in 2008 but has no intention of retiring any time soon. He has already supervised 50 master's dissertations, $40 \mathrm{PhD}$ theses, and more than 100 scientific initiation students. In addition, he has worked with 22 postdoctoral researchers and PhD students from other Brazilian and foreign research laboratories. He also acts as an ad-hoc advisor to the main research funding agencies in Brazil and national and international scientific journals in the area of analytical chemistry. Furthermore, he had more than $\mathbf{3 0 0}$ papers presented at national and international scientific events and over 190 published articles; an $\mathrm{H}$ index/number of citations of approximately 33/4036 on the Web of Science, 33/4409 on Scopus, 33/4365 on Research Gate, 33/4387 on Mendeley and 41/6013 on Google Scholar. This score is greater than $97.5 \%$ of Portal Research Gate members. 
Mário Ugulino is an active member of the scientific community, having worked as president of the organizing committee of the $14^{\text {th }}$ Brazilian Meeting of Analytical Chemistry, held from October 7 to 11, 2007, in João Pessoa, Paraíba, Brazil; a member of the CNPq Advisory Committee for chemistry in 2008 and from July 2013 to June 2016; a member of the Coordination of Superior Level Staff Improvement (CAPES) Advisory Committee for the evaluation/conceptualization of graduate programs in chemistry from 1999 to 2001 and from 2010 to 2012; a member of the Management Committee of the National Institute of Advanced Analytical Sciences and Technologies (INCTAA/CNPq) since 2009; a coordinator of the postgraduate program in chemistry at the UFPB from 1989 to 1991, from 1997 to 2002, and from 2010 to 2012; and as a coordinator of the CNPq registered research group named "Group of Instrumentation and Automation in Analytical Chemistry / Chemometrics of Paraíba" since 1988.

He is currently the coordinator of several research projects and scientific and technological collaborative projects at national and international level, funded by the main Brazilian research funding agencies: CAPES, CNPq, and the Funding Authority for Studies and Projects (FINEP). He works with his students to develop instrumentation and automatic methods of analysis for the determination of different analytes and/or the detection of contaminants in water, beverages, food, medicines, and fuels.

\section{When were you first introduced to chemistry? Did you have an influencer, such as a teacher?}

My first contact with chemistry was during practical classes in the chemical, physical, and biological sciences during the $7^{\text {th }}$ grade at the elementary state school Liceu Paraibano. I owe my great passion for chemistry to what I learned from Professor of General Chemistry, Dr. Josué Eugênio Viana, Professor of Physical Chemistry, Dr. Natarajan Subramanian, and to several other professors of the chemistry undergraduate course of the UFPB.

When did you decide to focus on chemistry? What motivated you in this decision? How were the early stages of your career?

At the end of high school, I did not have a definite vocation, because I was equally interested in chemistry, physics, and mathematics. I chose by chance to take the entrance exam for the Bachelor's degree in Industrial Chemistry, and in the first semester I fell in love with Chemistry. For this reason, I decided that chemistry teaching/researching would be my profession. In the second semester, I became a teaching assistant in the discipline of general chemistry, and following my graduation I became a statutory teaching assistant in other chemistry disciplines, assisting the teachers in the preparation and follow-up of practical classes, and helping the students with their school work.

What are your lines of research? What work are you currently developing? You have published many scientific papers. Are there any to highlight?

There are many jobs for which I have passion, I cannot highlight one. I have been working for several years, alongside my students, in the following lines of research:

-Instrumentation and automatic systems for chemical analysis: this involves the development of instruments, methodologies, and automatic systems for flow analysis, such as spectrometers, potentiostats Igalvanostats, photometers, luminometers, and FIA and flow-batch systems.

-Chemometric methods in analytical chemistry: this involves the development of algorithms and chemometric methods for: (a) first- and higher-order multivariate classification and calibration; (b) pretreatment of analytical data (filtering, smoothing, compression, baseline correction, and selection of variables and samples, etc); and (c) transfer of multivariate models employing NIR, UV-Vis and molecular fluorescence spectrometry, voltammetry, liquid chromatography and gas chromatography, etc.

-Analytical methods based on digital images: this involves the development of systems for univariate and multivariate analysis using digital images obtained from scanners, digital cameras (webcam), and cell phones. These digital images are treated using RGB (red, green, blue), HSI (hue, saturation, and intensity), CMYK (cyan, magenta, yellow, and black), and grayscale, and chemometric techniques. 
-Microfabrication in analytical chemistry: this involves the development of automated microfabricated systems using ultraviolet deep photolithography with commercial resin based on urethane and acrylate oligomers.

-Development of electroanalytical methods: this involves electrochemical oxidation/reduction studies using different types of electrodes, such as vitreous carbon and boron doped diamond, and the development of methods for the voltammetric determination of toxins, pesticides, and polycyclic aromatic hydrocarbons PAHs in food, beverages, and environmental matrices.

What is the importance of coordinating the LAQA for you?

Being the LAQA coordinator is a huge passion. It was extremely difficult to set up this laboratory due to financing issues in Paraíba. I stay at the LAQA for at least 10 hours every day, except when I am traveling, in meetings, in classes, or resting at weekends and on holidays.

Do you keep informed about the progress of chemistry research? What is your opinion of the current progress of chemical research in Brazil?

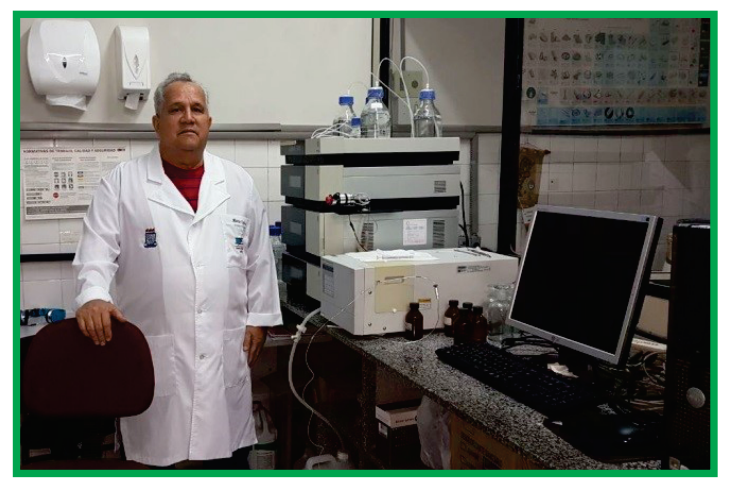
What are the latest advances and challenges in scientific research in Brazil?

I always try to stay well informed of chemistry research in my country and in the world. Brazil is very well developed and has made great progress in almost all areas of chemistry compared with any first world country. However, I and several researchers are extremely concerned about the lack of investment in research and education in Brazil, especially in recent years. We urgently need to reverse this situation, otherwise Brazil will see a decline in the advances made in recent decades and there will be a serious risk of losing great researchers to other countries.

For you, what have been the most important recent achievements in the world of analytical chemistry research? What are the landmarks?

There have been major and important milestones in analytical chemistry in recent decades. I could say that, for example, the coupling of analytical instrumentation to microcomputers in the late 1970s was an important milestone. However, with the generation of enormous amounts of data using these instrumentations, the development of chemometrics for the treatment of these data has been a fundamental framework for analytical chemistry. It is also worth mentioning the resurgence of NIR spectroscopy in the late 1980s, instrumentation hyphenation, and the emergence of laser-induced breakdown spectroscopy (LIBS) more recently. Nowadays, I find the use of nanotechnology, digital and hyperspectral images, and the generation of second-, third-, and fourth-order analytical data treated using higher-order chemometric techniques to be interesting landmarks.

There are several scientific meetings in the area of chemistry held in Brazil and worldwide. To you, how important are these meetings? How do you see the development of national meetings for chemistry in Brazil?

These scientific meetings are of fundamental importance for the exchange of ideas between researchers and students. Since the early 1980s, I have participated effectively at the Annual Meetings of the Brazilian Chemical Society (RASBQ) and the National Meeting of Analytical Chemistry (ENQA), which are important events for the growth of chemistry and analytical chemistry in Brazil.

You have already received a few awards. What is it like to receive this kind of recognition? What is the importance of these awards for the development of science and new technologies?

Some papers presented by my students at scientific events have been awarded, and others received an honorable mention at the UFPB. I am extremely happy to have been a professor/researcher honored for relevant contribution to analytical chemistry at the $15^{\text {th }}$ National Meeting on Analytical Chemistry \& $3^{\text {rd }}$ Ibero-American Congress on Analytical Chemistry held in Salvador in October 2009. An interesting fact 


\section{Interview}

that also honored me was to have been invited and written together with Roberto Kawakami Harrop Galvão the chapter: RKH Galvão and MCU Araújo "Variable Selection" In: Brown SD, Tauler R, Walczak B (eds.) "Comprehensive Chemometrics : Chemical and Biochemical Data analysis", vol. 3, pp. 233-283, Elsevier, Oxford, 2009.

For you, what is the importance of the support of research funding agencies (CAPES and São Paulo Research Foundation (FAPESP), among others) for scientific development in Brazil?

Allocation of resources to researchers by development agencies is of fundamental importance for the development of science in Brazil. Universities do not have the financial resources to pay for scientific and technological research in the country. Therefore, we researchers rely heavily on these development agencies.

How is a career in analytical chemistry? What advice would you give to a newcomer to this area?

I am extremely passionate about my career as a professor/researcher in analytical chemistry. I do not have advice specifically for a professional in this area. My advice is for professionals from any area. Do everything in your professional life with passion and dedication. If you do not have passion for your profession, immediately seek another profession that will provide this. Doing things in life without passion can be very sad. Everything you do with passion and dedication brings you good results and happiness. 